\title{
A escola, o fracasso e a psicologia: reflexões à luz da teoria histórico-cultural
}

Débora Cristina Piotto*

RESUMO: A história da participação da psicologia, enquanto ciência e prática profissional, na explicação para o fracasso escolar mostra que ela tem, de maneira geral, contribuído para a manutenção desse fenômeno, ao atribuir as suas causas às crianças pobres e suas familias. Partindo desse histórico, o objetivo do artigo é discutir aspectos de uma teoria psicológica, a saber, a teoria ou psicologia histórico-cultural, procurando refletir em que medida eles podem fornecer outros modos de entendimento sobre o fracasso escolar, contribuindo também para o seu enfrentamento. Assim, inicialmente, o texto discorre sobre o que se tem denominado de fracasso escolar, fornecendo dados que o caracterizem. Em um segundo momento, discute-se a relação entre fracasso escolar e psicologia, e apresentam-se algumas ideias da teoria histórico-cultural, enfocando suas decorrências para a explicação desse fenômeno. Dessa forma, o artigo está dividido em três partes ao final das quais seguem as considerações finais.

PALAVRAS-CHAVE: Psicologia. Fracasso escolar. Teoria histórico-cultural.

\section{School, failure and psychology: reflections in the light of historical-cultural theory}

\begin{abstract}
The history of the participation of psychology, as science and professional practice, in the explanation for school failure shows that it has, in general, contributed to the maintenance of this phenomenon, by attributing its causes to poor children and their families. Based on this history, the objective of the article is to discuss aspects of a psychological theory, namely, historical-cultural theory or psychology, trying to reflect to what extent they can provide other ways of understanding school failure, and also how they can contribute to cope with it. Thus, initially, the text discusses what has been called school failure, providing data that characterize it. In a second step, the relationship between school failure and psychology is discussed, and some ideas of historicalcultural theory are presented, focusing on their consequences for the explanation of this phenomenon. Thus, the article is divided into three parts at the end of which follow the final considerations.
\end{abstract}

KEY-WORDS: Psychology. School failure. Historical-cultural theory.

* Doutora em Psicologia Escolar e do Desenvolvimento Humano pelo Instituto de Psicologia da Universidade de São Paulo (USP) e docente na Faculdade de Filosofia, Ciências e Letras de Ribeirão Preto / USP. Endereço eletrônico: dcpiotto@usp.br 


\section{Introdução}

O fracasso escolar tem sido a marca da educação escolar brasileira desde que ela foi alçada à condição de sistema de ensino no século XIX. Entendido como o não benefício do que a escola deveria oferecer, tal fracasso já se revestiu de diferentes formas ao longo da história de nosso sistema educacional $^{1}$.

Em um primeiro momento, o fracasso escolar foi representado pelo não acesso a equipamentos educacionais quando a falta de escolas ou de vagas era uma realidade em grande parte do país. Isso resultava em um quadro marcado, por exemplo, por uma taxa de analfabetismo de $50 \%$ da população brasileira na década de 1950 (FERRARI, 1985).

Posteriormente, tendo-se, relativamente, equacionado o problema do acesso, o fracasso passou a ser representado pelo fato de que, muito embora crianças e adolescentes ingressassem na escola, eles não permaneciam nela, resultando em evasão escolar. Esse entendimento foi objeto de polêmica nos anos 1980 e modificado a partir de estudos como os realizado por Ribeiro (1991) que mostraram que o maior problema da educação escolar brasileira não era a evasão, mas sim a repetência. Tais estudos mostraram, por exemplo, que, de cada 1.000 alunos que ingressavam no antigo primeiro grau, apenas metade seguia para a $2^{\mathrm{a}}$ série e $30 \%$ alcançavam a $8^{\mathrm{a}}$ série sem reprovações. Esses índices redundavam no fato de que, apesar de as crianças brasileiras permanecerem oito anos e meio na escola, elas concluíam apenas seis séries de escolaridade na década de 1980 (RIBEIRO, 1991).

Assim, tendo em vista esses preocupantes índices, e a discussão sobre a questão da repetência, nos anos 1990 foram implementadas políticas educacionais de combate ao fracasso escolar, dentre as quais podemos citar, para o estado de São Paulo e a título de ilustração, a implantação do Ciclo Básico e do regime de progressão continuada. Os resultados dessas políticas foram regularização do fluxo escolar, ampliação do acesso à escola e melhorias nas estatísticas educacionais.

Atualmente, as taxas de atendimento na educação básica são as maiores da história escolar brasileira. $\mathrm{O}$ acesso ao ensino fundamental encontra-se universalizado, a taxa de atendimento na préescola é de 95\% e no ensino médio está em torno de 80\% (BRASIL / IBGE, 2013). Esses índices indicam que a maior parte da população brasileira tem ou teve acesso à escola. Mas, isso significa que todos tem se beneficiado dela? Infelizmente, dados educacionais atuais revelam que não.

Pesquisa realizada em 2018 mostra que quase 30\% da população de mais de 15 anos é analfabeta funcional (AÇÃO EDUCATIVA; IPM, 2018). Isso significa que aproximadamente um terço das pessoas que estão ou já estiveram na escola não conseguem, por exemplo, localizar informações em um

\footnotetext{
${ }^{1}$ Apesar de o fenômeno "fracasso escolar" ser (ou ter sido) também realidade em muitos outros países, neste texto deternos-emos na discussão da realidade educacional brasileira.
} 
calendário. Além disso, 15\% das crianças com oito anos de idade e que estão regularmente matriculadas no ensino fundamental não estão alfabetizadas (BRASIL, 2014). E apenas 1,6\% dos estudantes do último ano do ensino médio apresentaram a proficiência em língua portuguesa esperada para esse nível de escolarização (MEC/INEP, 2017).

Assim, seja por não ter acesso à escola, ou por ter acesso e repetir, e depois evadir, ou ainda por nela permanecer, mas não aprender, o fracasso escolar tem sido a marca da educação brasileira ao longo de sua história, significando que grande parte da população não tem se beneficiado do que a escola deveria oferecer.

Nesse quadro crônico, a Psicologia, enquanto conhecimento e prática profissional, tem se feito presente.

\section{Psicologia e fracasso escolar}

A constituição da Psicologia, enquanto ciência no final do século XIX e início do XX, ocorreu estreitamente relacionada a um contexto de expansão do sistema escolar na Europa e nos EUA (PATTO, 1990). Nesse momento de crescente e inédito aumento de acesso à escola, as desigualdades sociais não tardaram a ser reapresentadas em seu interior, tornando-se necessário explicar as diferenças de rendimento escolar entre as crianças sem ferir a principal crença do século retrasado de que todos poderiam ascender a melhores condições de vida a depender de seu mérito. Essa tarefa coube à nascente psicologia, que, ao assumi-la, conciliou sua autoafirmação enquanto ciência, desenvolvendo técnicas que permitiriam a aferição de diferenças individuais, e a necessidade de preservação do ideário meritocrático (PATTO, 1997).

Assim, por meio, por exemplo, de testes de QI (Quociente de Inteligência), e sem considerar a natureza desses tipos de avaliações psicométricas, seus contextos de produções, as concepções de inteligência que os embasam, os conteúdos das questões que requerem aprendizagens escolares, a relação desigual de poder na situação de testagem, entre outros fatores discutidos por diversos trabalhos como, os de Patto (1997) e Silva (1997), a Psicologia passa a atestar que os diferentes desempenhos escolares obtidos pelas crianças são resultados das diferenças individuais existentes entre elas. Explica-se e justificase, dessa forma, não só os desiguais rendimentos escolares, mas também as desigualdades nos níveis educacionais alcançados com os subsequentes desiguais postos de trabalhos e condições de vida daí advindos. Se a todos são dadas as mesmas oportunidades e alguns se saem melhores que outros, e se a ciência prova que isso ocorre porque alguns são mais capazes ou mais inteligentes, está resolvido o dilema do início do século XX. Ou ainda, como afirma Hobsbawm (2012):

...o mundo da classe média estava livremente aberto a todos. Portanto, os que não conseguiam cruzar seus umbrais demonstravam uma falta de inteligência pessoal, de força moral ou de energia que automaticamente os condenava (...) a uma herança racial 
ou histórica que deveria invalidá-los eternamente, como se já tivessem feito uso, para sempre, de suas oportunidades. (p. 277)

A participação da Psicologia na explicação do fracasso escolar assumiu também outras formas ao longo da história de sua relação com a educação. Assim, por exemplo, tal participação objetivou-se no que se convencionou denominar de "Teoria da Carência Cultural". Conjunto de pesquisas realizadas nos Estados Unidos nas décadas de 1950 e 1960, e que chegou ao Brasil nos anos 1970, essa teoria afirmava que os resultados escolares inferiores das crianças de meios populares poderiam ser explicados por deficiências, das mais diversas ordens (linguísticas, cognitivas, psíquicas, motoras), causadas, por sua vez, pela carência cultural dessas crianças e suas famílias (ASBAHAR; LOPES, 2006). Ilustração disso seria o fato, por exemplo, de que as crianças pobres, por viverem em ambientes muito ruidosos, desenvolveriam um mecanismo de defesa contra sons diferentes e, por essa razão, ao ingressarem na escola, não aprenderiam palavras novas, tendo dificuldades para se alfabetizar (POPPOVIC, 1972). Assim, a partir de instrumentos de investigação incipientes e orientados por concepções de classe na definição de parâmetros de desenvolvimento saudável, esse conjunto de pesquisas explicou, durante, principalmente as décadas de 1970 e 1980, os problemas escolares das crianças pobres brasileiras localizando-os na esfera individual (PATTO, 1984) ${ }^{2}$.

Em um estado arte da pesquisa sobre o fracasso escolar, Angelucci et al. (2004) fazem um resgate histórico das explicações para esse fenômeno desde a década de 1940 e analisam a produção científica dos anos 1990. No primeiro período analisado, as autoras localizam uma forte presença da explicação psicológica o que as leva a afirmar que a psicologia é marca de origem da pesquisa educacional brasileira no tocante à explicação sobre o fracasso escolar. Tendo passado por diversos períodos marcados por predominância de diferentes tipos de explicação, e após analisarem as explicações mais recentes para o fracasso escolar, as pesquisadoras concluem que há continuidade na concepção psicologizante da explicação para esse fenômeno, que reduz a uma dimensão - a saber, a psicológica ou individual - a explicação de um fenômeno psicossocial complexo e multi-determinado (ANGELUCCI et al., 2004).

Esse tipo de explicação reducionista para o fracasso escolar encontra oposição em outras áreas do conhecimento, dentre as quais destacamos a sociologia da educação e o trabalho do sociólogo francês Pierre Bourdieu. Esse autor dedicou grande parte de sua obra a mostrar que, diferentemente do que se acreditava, ou se pressupunha, a escola não é neutra, nem promotora dos melhores ou detentores de maior mérito (NOGUEIRA; NOGUEIRA, 2004). Ao contrário disso, Bourdieu discute que o sistema de ensino contribui para a reprodução social por meio da sanção, pela escola, da transmissão do capital cultural herdado da família. Entendendo que esse capital é um "privilégio cultural” (BOURDIEU, 2004), um tipo de cultura que gera dividendos na escola, e que é desigualmente distribuído entre os grupos

\footnotetext{
${ }^{2}$ Essas ideias ainda são bastante utilizadas para a explicação do fracasso escolar; mas, a partir da década de 1980 elas passaram a ser fortemente criticadas também dentro da área da psicologia, como atestam, por exemplo, os trabalhos de Patto (1984, 1990, 1997).
} 
sociais, o autor afirma que a escola legitima essa herança ou privilégio cultural como dom ou capacidade individual (BOURDIEU, 1998).

Não obstante essas e outras contribuições de áreas de conhecimento, como a sociologia da educação, a Psicologia, de forma geral, continua compreendendo os problemas escolares como sendo causados por fatores individuais inerentes aos sujeitos (TULESKI; EIDT, 2007). Dificuldades de aprendizagem escolar são os motivos mais comuns de encaminhamentos a psicólogos que, via de regra, encontram no indivíduo (ou no máximo em suas famílias) as causas para as queixas apresentadas (FACCI; EDIT, 2018). Diagnósticos de déficits de atenção, hiperatividade, deficiências intelectuais, dislexias, dislalias, discalculias, transtorno opositor são resultados comuns provenientes das avaliações psicológicas que redundam em indicações para psicoterapias, ludoterapias, orientação familiar e encaminhamento para tratamento medicamentoso.

Assim, a psicologia, juntamente com outras ciências, vem contribuindo para um fenômeno de medicalização de questões sociais, dentre elas, a aprendizagem escolar. Esse quadro tornou o Brasil o segundo maior consumidor de metilfenidado - princípio ativo de drogas para tratamento de hipertatividade como ritalina e concerta - do mundo, depois apenas dos Estados Unidos (ASBAHR; MEIRA, 2014). Esses medicamentos, que possuem vários e graves efeitos colaterais, incluindo risco de morte, têm se tornado cada vez mais comuns e naturalizados em ambientes escolares brasileiros (MOYSÉS, 2009) $)^{3}$.

Assim, percebemos que as relações entre psicologia e fracasso escolar têm se configurado de modo que as explicações que essa ciência, de forma geral, vem fornecendo para o fenômeno contribuem grandemente para a sua manutenção. Nesse contexto, seria possível pensar em uma contribuição da psicologia que oferecesse outros modos de entendimento para o fracasso escolar?

Consideramos que sim. E a partir da apresentação de alguns aspectos da psicologia histórico cultural pretendemos discutir essa questão.

\section{A teoria histórico-cultural}

Na recém-criada e pós-revolucionária União das Repúblicas Socialistas Soviéticas (URSS), Lev S. Vigotski e um conjunto de pesquisadores russos, dentre os quais Alexis Leontiev e Alexander Luria, grupo que ficou conhecido como "tróika", passaram a trabalhar, a partir de 1924, em um projeto científico coletivo para a construção de uma nova teoria psicológica, que formulasse uma explicação para o fenômeno humano, contemplando-o em sua complexidade e totalidade. Para isso, desenvolveram um novo método de pesquisa a partir do materialismo histórico-dialético de Karl Marx e propuseram que,

\footnotetext{
${ }^{3}$ A despeito da predominância de uma concepção e práticas reducionista em relação à explicação e ao trabalhos em relação ao fracasso escolar e às crianças que apresentam dificuldades de aprendizagem, é preciso destacar que vários grupos de psicólogos brasileiros têm construído outras formas de explicar e lidar com as queixas escolares. A esse respeito, e apenas a título de ilustração, ver, por exemplo, Souza (2010, 2007), Lessa e Facci (2011).
} 
assim como os demais fenômenos sociais, também o fenômeno humano tem história e materialidade (VIGOTSKI, 2018).

Partindo desse método, Vigotski e seus colaboradores afirmaram que o desenvolvimento humano pode ser explicado pela história cultural de um determinado grupo social. (VAN DER VEER;VALSINER, 2014). Assim, os limites e as possibilidades do desenvolvimento são dados pela história da produção cultural humana e pelas condições de sua apropriação (VIGOTSKI, 2018).

De acordo com a psicologia histórico-cultural, as características tipicamente humanas ou, nos termos dessa teoria, as funções psicológicas superiores, aquelas que nos diferenciam de todos os demais animais, como, por exemplo, fala, pensamento abstrato, memória e atenção voluntárias, somente podem ser desenvolvidas na relação com outros seres humanos. Assim, como afirma Leontiev (1978), cada indivíduo aprende a ser humano. Além disso, toda característica humana tem uma história filo e ontogenética; isto é, possui uma história no desenvolvimento da espécie humana e outra no desenvolvimento de cada ser humano, estando essas duas dimensões inter-relacionadas.

Exemplo paradigmático dessa interrelação é a fala. Segundo Vigotski (2007) ${ }^{4}$, a língua é uma das maiores produções culturais da história da humanidade. E, ao se apropriar dela, cada indivíduo atualiza em si essa história, modificando-se e humanizando-se (VIGOTSKI, 2018). Originada de uma necessidade de comunicação social advinda da atividade humana, a fala, quando se desenvolve em cada ser humano, atende, em um primeiro momento, a essa mesma necessidade. Assim, é em função da necessidade de nos comunicarmos, e estando imersos em um contexto falante, que aprendemos a falar. E, analogamente ao que ocorreu na história da humanidade, posteriormente, na ontogênese, a fala passa a desempenhar também outro papel, a saber, o de organização do pensamento, mudando por completo a sua natureza. A apropriação do sistema linguístico organiza e modifica todos os nossos processos mentais (VAN DER VEER; ZAVERSHNEVA, 2018). Da mesma forma que Marx afirma que o homem constrói instrumentos e ao utilizá-los modifica-se a si próprio, Vigotski afirma o mesmo em relação à língua, entendendo a palavra também como um instrumento, mas de ordem simbólica. Nesse sentido, graças à língua a consciência individual não se restringe à experiência pessoal e às observações de cada pessoa, uma vez que, com a sua apropriação, o conhecimento de toda a humanidade pode tornar-se propriedade de cada um (PALANGANA, 1998).

Nessa mesma direção, assim como a fala, também a escrita - cuja apropriação (inexistente, inadequada ou insuficiente) entendemos estar na base do fracasso escolar - tem uma história no desenvolvimento da humanidade e de cada ser humano. Segundo a psicologia histórico-cultural, a escrita é uma produção humana que atendeu a uma necessidade advinda das relações sociais. Ela é instrumento simbólico que amplia nossas potencialidades, ou conforme Oliveira (2005):

\footnotetext{
${ }^{4}$ No presente trabalho, reportar-nos-emos à tradução argentina Pensamiento y habla (VIGOTSKI, 2007), em vez da tradução brasileira (VIGOTSKI, 2001), por considerarmos que algumas passagens estão mais bem esclarecidas naquela obra.
} 
A escrita seria uma espécie de ferramenta externa, que estende a potencialidade do ser humano para fora de seu corpo: da mesma forma que ampliamos o alcance do braço com o uso de uma vara, com a escrita ampliamos nossa capacidade de registro, de memória e de comunicação. (p. 63).

Entendendo a escrita como uma atividade cultural complexa, Vigotski denomina esse sistema de representação como simbolismo de segunda ordem (VIGOTSKI, 1995). Ou seja, a linguagem escrita é, em um primeiro momento de seu desenvolvimento filo e ontogenético, a representação de uma representação. A palavra escrita é uma representação, neste formato, da palavra falada, que, por sua vez, é uma representação generalizada da realidade (VIGOTSKI, 2007). O autor afirma que toda palavra é uma generalização, remetendo a um conceito, a uma ideia geral de algo e não a determinadas coisas, coleção de objetos ou somatória de eventos na mente (VIGOTSKI, 2007). Contudo, com o seu desenvolvimento, a linguagem escrita passa a ter também um funcionamento próprio, com regras específicas, tornando-se (ou podendo tornar-se), um simbolismo de primeira ordem (VIGOTSKI, 1995).

E, tendo se desenvolvido na história da humanidade em função de uma necessidade, para que uma criança se aproprie da escrita, assim como ocorreu em relação à fala, ela precisa ter a necessidade de escrever. Ou, como afirma Vigotski (1995): "Isto requer que a escrita passe a ser um elemento da vida da criança como é, por exemplo, a fala.” (p. 203, tradução nossa). É preciso que essa forma de linguagem se torne necessária também para ela, de modo que ela compreenda e apreenda suas funções sociais. Estabelecendo uma relação entre o desenvolvimento da escrita na história da humanidade e na história de cada ser humano, Vigotski (1995) afirma que:

Para que a criança atinja essa descoberta fundamental [o uso de signos de escrita para representar os símbolos verbais da palavra], deve entender que não só pode desenhar coisas, mas também a fala. Essa foi a descoberta que levou a humanidade ao método genial de escrever por letras e palavras, e essa mesma descoberta leva a criança a escrever as letras. (p. 197, tradução nossa).

Estabelecendo analogias entre os processos de apropriação da fala e da linguagem escrita, Vigotski afirma que da mesma forma que as crianças aprendem a falar, elas podem aprender a ler e a escrever (VIGOTSKI, 1995). Mas, diferentemente do que ocorre com a fala, para a aprendizagem da escrita é preciso uma organização educacional intencional para que isso ocorra. Assim, se de um lado o processo de apropriação dessa linguagem está apoiado na imersão da criança em uma sociedade letrada, por outro, esse processo apoia-se também fortemente em processos de intervenção deliberada que ocorrem típica e principalmente na escola (OLIVEIRA, 1996). Vigotski discute que a possibilidade de apropriação da escrita pela criança está relacionada a condições criadas anteriormente no desenvolvimento infantil. Entendendo a escrita como parte de um longo processo de desenvolvimento da função simbólica na criança, Vigotski afirma que a brincadeira de faz-de-conta (ou jogo de papéis) e o desenho criam as condições necessárias para o desenvolvimento da linguagem escrita na infância. Nesse sentido, o autor postula a necessidade de uma intervenção intencional para a apropriação da escrita, já que, segundo ele: 
O educador deve organizar a atividade infantil para passar de um modo de linguagem escrita a outro, deve saber conduzir a criança através dos momentos críticos e inclusive à descoberta de que não só pode desenhar objetos, mas também a fala. Mas este método de ensino da escrita pertence ao futuro. (Vigotski, 1995, p. 203, tradução nossa).

Embora Vigotski tenha escrito este texto em 1931 e estivesse referindo-se especialmente ao ensino na ex-União Soviética, seu comentário parece ser atual e válido também para a realidade educacional brasileira. Sempre tendo como mote o combate ao fracasso escolar, nossas políticas educacionais têm promovido o oposto do que se deveria fazer para garantir o aprendizado da escrita. Estimula-se (tácita ou explicitamente), por exemplo, a antecipação da alfabetização, levando-se para as etapas finais da educação infantil ou para os anos iniciais do ensino fundamental, exercícios motores mecânicos e repetitivos, retirando das crianças possibilidades de brincarem e desenharem. Com o objetivo de ensinar as crianças a lerem e a escreverem, e assim evitar o fracasso escolar, elimina-se justamente aquelas atividades que criariam as condições para que a linguagem escrita pudesse se desenvolver. Quase um século depois, o método indicado por Vigotski parece ainda pertencer ao futuro.

\section{Considerações finais}

Com base nos dados históricos e atuais apresentados no início deste artigo, percebemos que nosso sistema de ensino tem, de modo geral, fracassado crônica e recorrentemente em garantir a apropriação, para grande parte da população, de uma grande e importante parte da produção humana - a linguagem escrita.

Vimos que a psicologia, enquanto ciência e profissão, tem contribuído para a manutenção desse quadro ao responsabilizar os indivíduos pelo fracasso escolar, localizando neles as suas causas.

Assim, enquanto sociedade, e contando com respaldo dessa ciência, temos condenado crianças e adolescentes a responsabilizarem a si mesmas por um fracasso sistêmico, e a carregarem por suas vidas a crença de que não "dão para a escola" ou não são "bons de cabeça”, sentindo-se incapazes e inferiores.

A mudança de entendimento que a psicologia histórico-cultural traz para o fenômeno faz diferença. Ao explicitar os modos de se fazer humano sempre em um contexto relacional e, em especial, ao discutir a história do desenvolvimento da escrita e seus modos de apropriação, essa teoria contesta a explicação psicológica hegemônica que inculpa a criança pobre e sua família por um processo do qual elas são vítimas. Dessa forma, retirando o foco explicativo do indivíduo, é possível atentar-se para os condicionantes políticos, históricos e sociais que não têm permitido ou garantido adequadamente o direito à educação.

Tendo aqui nos valido da discussão de Pierre Bourdieu para o entendimento do papel da escola na sociedade capitalista, não se trata, portanto, de defender uma visão ingênua de escola redentora ou salvadora. Tampouco se trata de desconsiderar os desiguais contextos de leitura e escrita em que as 
crianças estão inseridas. Pois se é verdade que também as camadas populares valem-se da escrita em um mundo letrado, como, mostram, por exemplo, trabalhos como os realizados pelo sociólogo francês Bernard Lahire (1997), desconsiderar as desigualdades no uso, na fruição e na fluência da linguagem escrita é ignorar a própria desigualdade social. Assim, trata-se aqui, apenas, de reconhecer possibilidades de ensino dadas as atuais condições concretas de existência da educação escolar brasileira. Trata-se de defender que crianças pobres podem aprender a ler e a escrever; e que se elas chegam analfabetas no sétimo, oitavo ou nono ano isso não se deve a incapacidade. Apoiando-nos em Paulo Freire, acreditamos que: "Se não se pode pedir à escola, o que vale dizer, à educação formal, que se torne alavanca das transformações sociais, não se pense, por outro lado, que ela seja um puro reflexo do sistema que a engendra". (1980, p. 7).

Numa apreensão dialética sobre o papel da escola, buscando compreendê-la em seu movimento e em suas contradições, entendemos ser possível atuar nas brechas existentes. E entendemos também que isso não é pouco. Apoiados na psicologia histórico-cultural, defendemos que crianças que conseguiram se apropriar da maior produção humana, possam também ter a oportunidade de tornarem suas próprias outras riquezas simbólicas produzidas por essa mesma humanidade e, assim, seguirem aprendendo e se desenvolvendo, transformando a si e ao mundo.

\section{REFERÊNCIAS}

AÇÃO EDUCATIVA; INSTITUTO PAULO MONTENEGRO. Indicador de Alfabetismo Funcional. (INAF): resultados preliminares. São Paulo: Ação Educativa; IPM, 2018.

ASBAHR, Flávia F. S.; MEIRA, Marisa E. M. Crianças desatentas ou práticas pedagógicas sem sentido? Relações entre motivo, sentido pessoal e atenção. Nuances: estudos sobre Educação, v. 25, n. 1, p. 97-115, jan./abr. 2014.

ASBAHR, Flávia F. S.; Lopes, Juliana S. “A culpa é sua”. Psicologia USP. SP, v.17, n1, 2006. p. 53-73.

BOURDIEU, P. A escola conservadora: as desigualdades frente à escola e à cultura. In: NOGUEIRA, Maria Alice; CATANI, Afrânio (Org.). Escritos de educaşão. Petrópolis: Vozes, 1998. p. 39-64.

BOURDIEU, Pierre; PASSERON, Jean-Claude. Os herdeiros: os estudantes e a cultura. Trad. Ione R. Valle e Nilton Valle. Florianópolis: Ed. UFSC, 2014.

BRASIL, Lei 13.005, de 25 de junho de 2014. Aprova o Plano Nacional de Educação - PNE e dá outras providências. 2014.

BRASIL. INSTITUTO BRASILEIRO DE GEOGRAFIA E ESTATISTICA. Censo demográfico 2010: educação, resultados da amostra. Rio de Janeiro: IBGE, 2013. 
FACCI; Marilda; EDIT, Nadia. Queixas escolares e intervenção dos psicólogos: a compreensão da psicologia histórico-cultural acerca do desenvolvimento da atenção. In: BEATÓN, G.A et al. Temas escolbidos na psicologia histórico-cultural: interfaces Brasil - Cuba. Maringá: Eduem (Ed. Da Universidade Estadual de Maringá), 2018.

FERRARI, Alceu. Analfabetismo no Brasil: tendência secular e avaliações recentes. Cadernos de Pesquisa, São Paulo, n. 52, p. 35-49, fev. 1985.

HOBSBAWM, Eric. A era do capital. $17^{\mathrm{a}}$ edição. RJ: Paz e Terra, 2012.

INEP/MEC. Instituto Nacional de Estudos e Pesquisas Educacionais Anísio Teixeira/Ministério da Educação e Cultura. Resultados do Saeb/2017. Brasília, 2017.

INSTITUTO BRASILEIRO DE GEOGRAFIA E ESTATISTICA. Pesquisa Nacional de Amostragem por Domicílio. (PNAD). 2011.

LAHIRE, Bernard. O sucesso escolar nos meios populares: as razões do improvável. São Paulo: Ática, 1997. LEONTIEV, Alexis N. O desenvolvimento do psiquismo. Lisboa: Horizonte Universitário, 1978.

LESSA, Patrícia Vaz de; FACCI, Marilda Gonçalves Dias. A atuação do psicólogo no ensino público do Estado do Paraná. Psicol. Esc. Educ., Maringá, v. 15, n. 1, p. 131-141, June 2011.

MOYSÉS, Maria Ap. Dislexia existe? Questionamentos a partir de estudos científicos. Transcrição de apresentação no evento "Dislexia, Subsidios para Politicas Públicas" promovido pelo Conselho Regional de Psicologia, São Paulo, 2009.

NOGUEIRA, M. A.; NOGUEIRA, C. M. M.. Bourdieu e a educação. Belo Horizonte: Autêntica, 2004.

OLIVEIRA, Marta Kohl. Pensar a educação: contribuições de Vygotsky. In: CASTORINA, J.A e cols. Piaget e Vygotsky: novas contribuições para o debate. SP: Ática, 2005.

OLIVEIRA, M. K. Does schooling always help to think better? In: IInd CONFERENCE FOR SOCIO-CULTURAL RESEARCH, 1996, GENEBRA. Abstracts... Genebra: [s.n.], 1996.

PALANGANA, Isilda C. Desenvolvimento e aprendiragem em Piaget e Vygotsky: a relevância do social. SP: Summus, 1998.

PATTO, Maria Helena. A produção do fracasso escolar - histórias de submissão e rebeldia. SP: TA Queiroz, 1990.

PATTO, Maria Helena. Para uma crítica da razão psicométrica. Psicologia USP. SP, v. 8, n1, 1997.

PATTO, Maria Helena. Psicologia e ideologia: uma introdução crítica à Psicologia escolar. SP: TA Queiroz, 1984.

POPPOVIC, Ana Maria. Atitudes e cognição do marginalizado cultural. Revista Brasileira de estudos pedagógicos. RJ, v. 57, n. 126, abr./junh. 1972.

RIBEIRO, Sérgio Costa. A pedagogia da repetência. Revista de Estudos Avançados. 12(5), 1991.

SILVA, Franklin Leopoldo. Conhecimento e razão instrumental. Revista Psicologia USP. Vol. 8, n. 1. 1997. p. 11-31.

SOUZA, Marilene Proença Rebello de. A queixa escolar e o predomínio de uma visão do mundo. In: Psicologia escolar: em busca de novos rumos. $5^{\text {a }}$ ed. SP: Casa do psicólogo, 2010. 
SOUZA, Marilene Proença Rebello de. Prontuários revelando os bastidores: do atendimento psicológico à queixa escolar. In: SOUZA, B.P. Orientação à queixa escolar. SP: Casa do psicólogo, 2007.

TULESKI, Silvana C.; EIDT, Nadia M. Repensando os distúrbios de aprendizagem a partir da psicologia histórico-cultural. Psicologia em Estudo, v. 12, n. 3, p. 531-540, set./dez. 2007.

VAN DER VEER, Rene; ZAVERSHNEVA, Ekaterina. The final chapter of Vygotsky's Thinking and Speech: A reader's guide. J HistBehav Sci. 2018; 54:101-116.

VAN DER VEER, Rene; VALSINER, Jann. Vygotsy: uma síntese. $7^{\text {a }}$ ed. São Paulo: Ed. Loyola, 2014.

VIGOTSKI, Lev S. Sete aulas de L. S. Vigotski sobre os fundamentos da pedologia. Tradução e organização: Zoia Prestes; Elisabeth Tunes. RJ: E-papers, 2018.

VIGOTSKI, Lev S. Pensamiento y Habla. Buenos Aires: Colihue, 2007.

VIGOTSKI, Lev S. A construção do pensamento e da linguagem. SP: Martins Fontes, 2001.

VIGOTSKI, Lev S. La prehistoria del desarollo del lenguaje escrito. In: Obras escogidas. Tomo III. Visor: Madri, 1995. 